\title{
Penguatan Sentra Kewirausahaan Pemuda Gampong Pante Rawa Aceh Besar Melalui Program Inkubator Bisnis Kemenpora
}

\author{
Akmal Saputra ${ }^{1}$, Cut Irna Liyana ${ }^{2}$ \\ ${ }^{1}$ Jurusan Sosiologi, Universitas Teuku Umar, Indonesia \\ ${ }^{2}$ Jurusan Sosiologi, Universitas Teuku Umar, Indonesia
}

\section{ARTICLE INFORMATION}

Received: February 19, 2020

Revised: April 19, 2020

Accepted: April 25, 2020

Available online: April 30, 2020

\section{KEYWORDS}

Business incubator, Strengthening of youth entrepreneurship centers

\section{CORRESPONDENCE \\ Phone: +6285372609407 \\ E-mail: akmalsaputra@utu.ac.id}

\begin{abstract}
A B S T R A C T
This article examines how the business incubator program by the Ministry of Youth and Sports (Kemenpora) through the Aceh Ummat Development Institute (LPU) in 2013 has influenced and given impact the Youth Entrepreneurship Center (SKP) in the Pante Rawa village, Kecamatan Kuta Malacca, Aceh Besar Regency. This study uses qualitative methods with purposive techniques, data collection techniques through in-depth interviews, documentation of activities and observation after the program is implemented. The results showed that the Business Incubator program implemented by the Ministry of Youth and Sport had an impact on the independence of youths in the villages, the formation of Youth Entrepreneurship Centers (SKP), encouraging entrepreneurship, impacting on creative, innovative values and youth participation in entrepreneurship, the realization of youth values togetherness at Pante Rawa village, Kuta Malaka sub-district, Aceh Besar District
\end{abstract}

\section{PENDAHULUAN}

Artikel ini mengkaji tentang bagaimana program Inkubator Bisnis yang diprogramkan oleh Kementerian Pemuda dan Olah Raga (Kemenpora) dapat memberikan dampak bagi penguatan Sentra Kewirausahaan Pemuda (SKP) di Gampong (desa) Pante Rawa Kecamatan Kuta Malaka Kabupaten Aceh Besar. Program Inkubator Bisnis diprogramkan oleh Kemenpora dan salah satunya bermitra dengan Lembaga Pengembang Ummat (LPU) di Aceh pada tahun 2013. Lembaga Pengembang Ummat merupakan salah satu LSM (Lembaga Swadaya Masyarakat) lokal di Aceh yang non profit (tidak berorientasi laba).

Program Inkubator Bisnis ini telah dilaksanakan pada tahun 2013 dengan membina Sentra Kewirausahaan Pemuda (SKP) di Gampong Pante Rawa dengan membentuk empat kelompok usaha budidaya ikan air tawar yaitu budidaya ikan lele dengan memanfaatkan lokasi persawahan dan rawa-rawa yang ada di Gampong Pante Rawa (Saputra, 2013).

Atas dasar itu kemudian penulis menilai bahwa program Inkubator Bisnis ini penting untuk dievaluasi sebagai salah satu bentuk penilaian terhadap program yang telah diimplementasi oleh Kemenpora pada tahun 2013 melalui salah satu mitranya Lembaga Pengembang Ummat di Aceh Besar.

Evaluasi merupakan tahapan akhir dari setiap program yang telah direncanakan dan diimplementasikan. Evaluasi merupakan salah satu metode untuk mengukur keberhasilan, kekurangan dan kegagalan salah satu program yang telah direncanakan sekaligus untuk memasang strategi pada programprogram berikutnya (Anna, Mannan, \& Srirahayu, 2019; Fernandez-Moral, Vidueira, Diaz-Puente, \& Nicolas, 2015; Matridi et al., 2015; Murdiansyah, 2014; Naufal \& Kusumastuti, 2010). Hasil evaluasi program pemberdayaan masyarakat bermanfaat untuk perencanaan program pada masa yang akan datang.

Inkubator Bisnis merupakan salah satu program nasional pemerintah yang dilaksanakan melalui Kementerian Pemuda dan Olah Raga (Kemepora) pada tahun 2013 yang bertujuan untuk menginkubasi para pengusaha untuk menjadi pengusaha pemula yang mandiri. Inkubator Bisnis diibaratkan sebagai Inkubator bagi bayi yang prematur yang berfungsi untuk memberikan sumberdaya agar menjadi manusia yang dewasa dan tangguh. Inkubator Bisnis juga bermakna sebagai lembaga yang berorientasi laba atau non laba yang akan mendampingi pengusaha untuk menjadi pengusaha yang mandiri dan tangguh (M.B.Zubakhrum et al., 2013).

Pada tahun 2013 Kemenpora membuka program Inkubator bisnis dengan tujuan untuk menginkubasi para pengusaha agar menjadi pengusaha pemula yang tangguh, mandiri dan menjadikan para pengusaha untuk dapat meningkatkan kemampuan dalam berwirausaha bagi Wirausaha Muda Pemula (WMP), Kelompok Wirausaha Pemuda (KWP), dan Sentra

Attribution-ShareAlike 4.0 International. Some rights reserved 
Kewirausahaan Pemuda (SKP) agar dapat mengembang usahanya (M.B.Zubakhrum et al., 2013).

Studi-studi tentang evaluasi program penguatan pemuda dan masyarakat dalam berwirausaha bukanlah studi-studi yang baru, namun telah banyak dilakukan baik oleh akademisi maupun para praktisi pekerja sosial. Penguatan pemuda dan masyarakat merupakan bagian daripada bagaimana memberdayakan dan mengembangkan masyarakat untuk menjadi masyarakat yang mandiri (Ogamba, 2018).

Berikut ini beberapa studi yang memiliki kesamaan dengan studi yang hendak penulis kaji yaitu mengevaluasi programprogram pengembangan dan pemberdayaan masyarakat di pedesaan. Studi Alfrojems, tentang pengembangan ekonomi kreatif, pariwisata dan modal sosial dalam mengentaskan kemiskinan di pedesaan, artikelnya bertujuan untuk mengidentifikasi upaya pengentasan kemiskinan melalui ekonomi kreatif, pariwisata dan modal sosial. Hasil penelitian menunjukkan penguatan modal sosial menjadi hal yang sangat penting dalam pengembangan pariwisata, ekonomi kreatif dalam upaya-upaya pengentasan (Alfrojems, 2019).

Studi berikutnya mengkaji tentang pemberdayaan masyarakat pesisir dalam upaya peningkatan ekonomi masyarakat. Pemberdayaan tentang budi daya ikan air tawar dan air asin yang dilakukan selama ini di desa belum dilakukan secara maksimal, perlu pendampingan agar mendapatkan hasil yang lebih baik. Hasil budidaya ikan air tawar juga harus diolah menjadi "barang jadi" agar mendapat keuntungan yang maksimal, tidak hanya sekedar menjual bahan "mentah" saja, begitu juga dengan budidaya ikan air asin, perlu pendampingan lebih lanjut dari pihak terkait (Iswari, Indrayani, \& Suwena, 2019).

Selanjutnya, evaluasi program pemberdayaan masyarakat pada penguatan kelompok budidaya ikan "Mandiri Saiyo" dengan output mengubah cara pandang masyarakat terhadap budidaya ikan, transfer pengetahuan tentang bagaimana budidaya ikan yang baik dan benar serta memberikan keterampilan terkait dengan pembuatan pakan untuk ikan. Penelitian ini menunjukkan bahwa meningkatnya stimulus dan semangat serta partisipasi masyarakat untuk memanfaatkan lahannya sebagai tempat budidaya ikan, lapangan kerja menjadi meningkat dan mengurangi pengangguran, meningkatkan pendapatan anggota, meningkatkan pengetahuan tentang budidaya ikan dan meningkatkan kemampuan untuk membuat pakan ikan. Namun terdapat juga beberapa faktor yang menghambat pelaksanaan program yaitu masih kurangnya manajemen organisasi, masih kurangnya kesadaran anggota kelompok, masih kurangnya kerja tim dan pemasaran hasil panen (Iswadi, 2019).

Penelitian lainnya juga dilakukan oleh Utami dan Khonitan tentang pemberdayaan berbasis "social enterpreneurship" pada bidang peternakan dan pertanian. Artikel ini menunjukkan bahwa proses pemberdayaan yang dilakukan adalah penyadaran, penguatan kapasitas dan pendayaan melalui otoritas masyarakat. Terdapat factor pendukung dan penghambat; faktor pendukung, yaitu: modal (uang) untuk kegiatan, partisipasi dan peran serta para tokoh; sedangkan faktor penghambat, yaitu: faktor kepemimpinan (leadership), kurang SDM (sumberdaya manusia) dibidang pertanian dan peternakan (Utami \& Khonitan, 2018).

Berikutnya studi Sidik dkk, tentang pemberdayaan masyarakat dengan menggunakan Badan Usaha Milik Desa yang menunjukkan bahwa desa Ponggok berhasil mentransformasikan masyarakat dari pemberdayaan masyarakat berbasis komunitas menuju pemberdayaan dengan memanfaatkan Badan Usaha Milik Desa yaitu Desa Wisata Alam dengan memanfaatkan sumberdaya milik bersama. Namun studi ini memperlihatkan bahwa pemberdayaan yang dilakukan belum menyentuh masyarakat dikalangan akar rumput (grassroot) (Sidik, Nasution, \& Herawati, 2018).

Berangkat pada latar belakang diatas dan studi literatur yang ada, maka artikel yang mengkaji tentang pemberdayaan masyarakat yang berkaitan dengan evaluasi program pemberdayaan, baik proses pemberdayaan, faktor pendukung dan faktor penghambat program dan bagaimana dampak yang dirasakan oleh masyarakat pasca program pemberdayaan masyarakat berakhir, telah banyak dikaji dan diteliti oleh para peneliti untuk berbagai kepentingan, baik untuk kepentingan akademik maupun kepentingan praktis dalam mengambil sebuah kebijakan.

Studi-studi sebelumnya berbicara soal evaluasi program pemberdayaan masyarakat, namun belum menyentuh secara utuh bagaimana mengevaluasi program dengan melihat input, proses, output dan outcome. Atas dasar diatas kemudian penulis mencoba untuk mengevaluasi program pemberdayaan melalui metode ini dengan melihat input, proses, output dan outcome. Penelitian ini berkontribusi dalam bidang ilmu pemberdayaan masyarakat terkait evaluasi dan dapat menjadi rekomendasi terhadap program pemerintah.

\section{METODE}

Penelitian yang mengkaji tentang bagaimana dampak bagi pemuda gampong khususnya Sentra Kewirausahaan Pemuda (SKP) pasca implementasi program Inkubator Bisnis di Gampong Pante Rawa Kecamatan Kuta Malaka Kabupaten Aceh Besar ini menggunakan penelitian kualitatif. Penelitian kualitatif merupakan penelitian yang bersifat deskriptif dan cenderung menggunakan analisis (Creswell, 2019; K.Denzin \& S.Lincoln, 2009; Sugiyono, 2013; Tong et al., 2007). Objek dan fokus penelitian ini adalah mengevaluasi atau mengkaji bagaimana program Inkubator Bisnis ini memberikan dampak pada penguatan pemuda atau Sentra Kewirausahaan Pemuda (SKP) di Gampong Pante Rawa Aceh Besar. Lokasi penelitian dilakukan di Gampong Pante Rawa Kecamatan Kuta Malaka Aceh Besar

Teknik penentuan informan dengan teknik purposive atau berdasarkan tujuan. Adapun orang-orang yang diwawancara adalah keuchik (kepala desa), sekretaris gampong, ketua pemuda, dan kaur-kaur (kepala urusan) pemerintahan gampong, kelompok-kelompok usaha budidaya ikan lele, direktur dan staf Lembaga Pengembang Ummat (LPU) sebagai pendamping dari kegiatan ini.

Teknik pengumpulan data yaitu wawancara mendalam, pengumpulan dan membaca dokumen-dokumen hasil kegiatan dan observasi kegiatan yang dilakukan oleh pemuda atau masyarakat. Untuk mewawancarai informan, penulis menyiapkan daftar wawancara terlebih dahulu sebagai petunjuk wawancara, pertanyaan tidak kaku seperti yang telah tertera pada daftar wawancara, pertanyaan-pertanyaan saat wawancara akan terus dikembangkan sesuai dengan kebutuhan data yang dibutuhkan.

Dokumen-dokumen yang dibutuhkan berupa laporan kegiatan dan proposal kegiatan dari pendamping yaitu Lembaga Pengembang Ummat, dokumen-dokumen lainnya berupa 
catatan-catatan kecil atau laporan milik pemerintahan gampong atau milik Sentra Kewirausahaan Pemuda (SKP). Observasi yang dilakukan adalah melihat bagaimana kondisi lahan yang dijadikan tempat budidaya lele, bagaimana proses budidaya, bagaimana partisipasi anggota atau kelompok budidaya dan bagaimana pemasarannya.

Teknik analisis data menggunakan triangulasi, baik triangulasi teknik (metode) maupun triangulasi sumber (informan). Data atau informasi yang didapat melalui observasi akan diuji kembali dengan melihat dokumen-dokumen yang ada atau diuji kembali dengan melihat hasil wawancara dengan informan. Sedangkan triangulasi sumber, yaitu data atau informasi dari informan "A" akan diuji kembali dengan Informan "B" atau "C" atau seterusnya, jika terdapat informasi atau datadata yang berbeda maka perlu cross chek kembali ke sumbernya (informan).

\section{HASIL DAN PEMBAHASAN}

Pemberdayaan masyarakat merupakan suatu mekanisme dimana setiap individu, organisasi dan masyarakat menjadi ahli dan memahami akan permasalahan yang sedang mereka hadapi (Vina Salviana Darvina Soedarwo, Nurul Zuriah, Ratih Yuliati, 2017 ;Iswari et al., 2019; Noor, 2011). Pemberdayaan masyarakat juga bermakna kekuasaan, daya atau power, masyarakat memiliki kekuasaan atau masyarakat memiliki daya dan kemampuan (Ife $\&$ Tesoriero, 2008).

Penguatan kapasitas pemuda atau penguatan Sentra Kewirausahaan Pemuda (SKP) merupakan bagian dari pemberdayaan masyarakat itu sendiri (Ogamba, 2018). Pada latar belakang diatas penulis telah menjelaskan sedikit bahwa Inkubator Bisnis merupakan program pemerintah pusat melalui Kemenpora dan Lembaga Pengembang Ummat (LPU) sebagai salah satu mitra untuk membina Sentra Kewirausahaan Pemuda (SKP) di gampong Pantee Rawa Kecamatan Kuta Malaka Kabupaten Aceh Besar.

Lembaga Pengembang Ummat atau yang disingkat dengan LPU merupakan lembaga swadaya masyarakat (LSM) lokal yang telah berdiri sejak tahun 2007 di Aceh Besar yang didirikan oleh para alumni dari Jurusan Pengembangan Masyarakat Islam UIN Ar-Raniry (dulu IAIN Ar-Raniry) salah satu kampus ternama di provinsi Aceh atau kampus "jantoeng hatee" rakyat Aceh. Fokus dari LSM ini bergerak pada bidang pengembangan dan pemberdayaan masyarakat, wilayah kerja mencapai keseluruh kabupaten dan kota di provinsi Aceh. LSM ini tidak berorientasi pada laba (non profit).

Berdasarkan wawancara dengan pihak pelaksana dan masyarakat maka dijelaskan bahwa program ini telah dilaksanakan sesuai dengan yang direncanakan. Hal ini dapat diukur dengan membaca peta antara input, proses dan output.

Berikut ini penulis akan mengulas temuan lapangan yang telah penulis pilih dan pilah, mulai dari perencanaan program (input), implementasi program (proses), hasil program (output) dan dampak dari program pemberdayaan masyarakat (outcome).

\section{Perencanaan Program (input)}

Perencanaan merupakan satu hal yang sangat penting untuk dilaksanakan pada setiap program pemberdayaan masyarakat, tanpa perencanaan yang baik maka pendamping program telah merencanakan sebuah kegagalan.
Berdasarkan data di lapangan, program penguatan kapasitas Sentra Kewirausahaan Pemuda (SKP) pertama sekali tahapan yang dilakukan oleh pendamping adalah perencanaan. Pendamping terlebih dahulu membuat perencanaan sebelum program pemberdayaan dilaksanakan. Perencanaan dipersiapkan dengan matang bersama tim yang telah ditunjuk untuk mendampingi program pemberdayaan. Perencanaan yang dilakukan adalah persiapan survei lapangan, koordinasi dengan pemerintah gampong, pemuda, koordinasi dan kerjasama dengan mitra ahli yang akan mendampingi program, teknik pemasaran, teknik menghitung untung dan rugi.

Perencanaan itu dituangkan dalam TOR (term of reference) yang berfungsi sebagai pedoman atau pegangan untuk melaksanakan kegiatan. Bagi pendamping program pemberdayaan, TOR sebagai pedoman dalam setiap tahapan program agar tidak bergeser dari yang telah direncanakan.

\section{Implementasi Program (proses)}

Survei lokasi pengembangan usaha Sentra Kewirausahaan Pemuda (SKP) merupakan tahapan kegiatan yang pertama, kegiatan ini bertujuan untuk memastikan lokasi atau lahan untuk budidaya air tawar (lele). Selain itu lembaga mitra/pendamping yaitu Lembaga Pengembang Ummat (LPU) juga memastikan kondisi sosial dan ekonomi (pendapatan) pemuda di gampong yang menjadi target kegiatan dimaksud, tujuannya adalah bahwa program pemberdayaan masyarakat yang akan diimplementasikan tidak salah sasaran.

Tim pendamping juga memastikan gampong tersebut benarbenar membutuhkan pendampingan atau layak untuk didampingi, bahwa saat ini gampong yang dimaksud memiliki tingkat kesejahteraan masyarakat yang masih sangat rendah, pendapatan masyarakat juga masih sangat rendah.

Kegiatan berikutnya adalah melakukan koordinasi dengan pihak pemerintah gampong untuk memastikan partisipasi pemuda yang akan terlibat dalam program penguatan kapasitas pemuda dibidang usaha budidaya ikan lele, sekaligus melakukan penguatan internal tim (pemuda) yang akan terlibat dalam kegiatan budidaya ikan lele dengan membentuk kelompok Sentra Kewirausahaan Pemuda (SKP).

Tahapan Kegiatan berikutnya adalah melakukan sosialisasi program kepada penerima manfaat (pemuda), bagaimana bentuk program yang akan dijalankan, dimana lokasi kegiatan, siapa saja yang akan terlibat dalam kegiatan dan bagaimana evaluasi dilakukan untuk pengembangan usaha dimasa mendatang. Sosialisasi juga bagian dari proses penyadaran masyarakat sekaligus memberikan semangat kepada masyarakat khususnya pemuda untuk lebih kreatif dan inovatif dengan memanfaatkan sumberdaya alam sekitar.

Proses penyadaran yang dilakukan salah satunya memberikan informasi penting bahwa budidaya ikan lele pada dasarnya sangat menjanjikan secara ekonomi, saat ini kebutuhan ikan lele dipasaran sangat tinggi, apalagi provinsi Aceh saat ini menjadi tempat paling menarik untuk dikunjungi oleh para wisatawan asing dan lokal, kuliner di Aceh sangat membutuhkan pasokan ikan lele salah satunya.

Pendamping program kemudian juga melakukan penguatan tim internal di lembaga pendamping yaitu Lembaga Pengembang Ummat untuk memastikan tim pendamping benarbenar solid untuk berpartisipasi dalam kegiatan pendampingan ini. Tanpa tim yang solid, program pemberdayaan masyarakat tidak akan berjalan sebagaimana diharapkan. 
Lembaga Pengembang Ummat (LPU) sebagai pendamping juga membangun kemitraan dengan para ahli yang akan melatih bagaimana melakukan budidaya ikan lele yang baik dan benar agar dapat menghasilkan pendapatan yang maksimal sekaligus melatih bagaimana teknik pemasaran, kemana saja harus dipasarkan hasil panen, perlu pemetaan lokasi pemasaran dan juga pemetaan potensi-potensi dimiliki gampong dan pemuda. Selain itu para ahli juga melatih bagaimana mengukur keuntungan dan kerugian dalam budidaya ikan lele.

Selanjutnya juga melatih bagaimana mengolah pakan dengan memanfaatkan sumberdaya alam yang ada dilingkungan itu sendiri, mengingat pakan yang dibeli dipasar tentu saja harganya cukup tinggi, maka kemudian masyarakat dilatih untuk mengolah pakan dari sumberdaya alam yang ada, misalnya keong mas yang ada di rawa-rawa kemudian direbus dan dicongkel dan dapat dimanfaatkan untuk pakan ikan lele, selain itu juga membangun kemitraan dengan rumah potong ayam dan pasar ikan, sisa-sisa dari rumah potong ayam dan ikan dapat digunakan untuk pakan ikan lele dengan biaya yang tergolong sangat ekonomis dibanding membeli pakan di toko.

Hasil observasi penulis, kolam lele dikerjakan oleh kelompok pemuda yang tergabung dalam kelompok Sentra Kewirausahaan Pemuda (SKP) yang telah dibentuk oleh tim pendamping. Lokasi kolam ini sebelumnya adalah rawa-rawa yang memiliki air yang sangat baik, sebelumnya rawa-rawa ini ditanami padi oleh masyarakat, namun setelah ada kesapakatan pemilik lahan, mereka sepakat lahannya digunakan untuk proses budidaya ikan lele.

Keterlibatan pemuda saat mengerjakan dan membangun kolam ikan lele menunjukkan bahwa partisipasi pemuda dalam membangun usaha bersama dinilai sangat baik, hanya saja perlu sedikit dukungan dan pemberian motivasi dari para pendamping. Masyarakat atau pemuda pada dasarnya memiliki potensi sumberdaya manusia yang sangat baik, hanya saja perlu dukungan dari pendamping.

Kolam ikan lele yang dibuatkan oleh kelompok pemuda berbentuk persegi panjang kemudian dibagi menjadi 4 (empat) bagian untuk 4 (empat) kelompok pembudidaya. Pada masingmasing bagian dibuatkan pembatas, Pembatas kolam dibuatkan dari bambu, kemudian juga dibuatkan tempat untuk lalu lalang pembudidaya guna mudah mengontrol kondisi kolam dan ikan lele.

Budidaya ikan lele ini menggunakan sistem "Kolam Jaring". "Kolam Jaring" memiliki keunggulan tersendiri, mudah bagi pembudidaya untuk mengontrol ukuran ikan lele dengan cara menarik jaring keatas melalui tali yang sudah disiapkan, kemudian ikan lele sangat mudah terpantau sudah seberapa ukuran ikan lele, Jika ada ikan lele yang masih ukurannya tidak sebanding dengan ukuran pada umumnya, maka ikan lele tesebut dipindahkan ke kolam yang lain (proses sortir). Terkadang pada umur yang sama, bisa jadi ukuran ikan lele berbeda dengan pada umumnya, hal ini diduga karena pada saat pemberian pakan, sebagiannya tidak mendapatkan pakan (tidak tercukupi), hasilnya kemudian ukurannya masih kecil.

Mengenai pemasaran, mereka telah membangun mitra dengan pasar-pasar yang ada di Kabupaten Aceh besar, hasil panen biasanya akan ada tim yang akan membeli hasil panennya, mereka biasanya langsung ke lokasi kolam dan menyelesaikan transaksi jual beli di lokasi budidaya ikan lele.

Bendahara yang dipilih oleh anggota maka akan mencatat uang masuk atau hasil penjualan dan uang keluar, misalnya biaya beli pakan, biaya perawatan ikan lele (obat-obatan), biaya perawatan kolam, konsumsi para pembudidaya dan yang paling penting mereka telah dididik untuk menyimpan sedikit dari keuntungan penjualan untuk keberlanjutan program budidaya ikan lele.

Pemilihan struktur kepengurusan dari Sentra Kewirausahaan Pemuda (SKP) diatur dalam rapat anggota bersama tim pendamping dan dihadiri oleh keuchik dan perangkat gampong lainnya, pemilihan anggota pengurus melibatkan partisipasi anggota secara demokratis, semua anggota berhak mengajukan diri dan mengajukan nama orang lain.

Untuk memastikan program ini berjalan, maka tim pendamping melakukan monitoring kegiatan. Pada saat program sedang berjalan, monitoring terus dilakukan oleh pendamping, jika ada hal-hal yang tidak sesuai maka akan dibicarakan dan didiskusikan dengan kelompok pembudidaya dan juga memberikan berbagai masukan agar proses budidaya dapat berjalan dengan baik dan mendapatkan keuntungan yang maksimal.

Pada saat telah selesai panen, maka seluruh anggota tim akan dilibatkan dan diadakan pertemuan sebagai wujud dari evaluasi pelaksanaan program. Pihak gampong, pihak pendamping, tenaga ahli dan tim pembudidaya akan duduk bersama untuk melakukan evaluasi saat pelaksanan kegiatan dan kembali merencanakan kegiatan budidaya berikutnya.

Evaluasi biasanya dilakukan pada tahap akhir dari kegiatan yang telah dilaksanakan. Evaluasi juga bermakna penilaian, evaluasi dapat dilakukan pasca selesai program pemberdayaan atau tiga bulan, enam bulan, satu tahun, tiga tahun, lima tahun atau bahkan sepuluh tahun setelah program pemberdayaan berakhir.

Untuk melakukan evaluasi program maka terlebih dahulu harus melihat apa program yang telah direncanakan (input) dan proses (implementasi) pelaksanaan program, apakah program yang dilaksanakan atau diimplementasikan telah sesuai dengan yang direncanakan?. jika tidak sesuai dengan yang direncanakan berarti program pemberdayaan mengalami pergeseran dan bahkan mungkin saja program itu dianggap gagal.

Lembaga Pengembang Ummat (LPU) sebagai tim pendamping juga mitra Kemenpora terus melakukan monitoring kegiatan selama kegiatan berlangsung. Monitoring dilakukan guna untuk memantau apakah yang dilaksanakan telah sesuai dengan yang direncanakan.

Pelaksanaan pelatihan untuk kelompok Sentra Kewirausahaan Pemuda (SKP) juga dilakukan monitoring, karena harus dipastikan bahwa penerima manfaat benar-benar memahami teori-teori atau teknik-teknik bagaimana melaksanakan kegiatan budidaya ikan lele, mulai persiapan kolam, pemberian pakan, kapan harus dipanen, kemana dipasarkan dan bagaimana menghitung laba dan rugi.

Berdasarkan temuan lapangan mengenai proses dan implementasikan program, penulis menilai bahwa Lembaga Pengembang Ummat (LPU) telah melakukan beberapa tahapan, mulai perencanaan dan juga pelaksanaan (implementasi), yaitu: melakukan survei lapangan, membangun komunikasi dan koordinasi dengan pihak penerima manfaat, melakukan koordinasi dengan pemerintah gampong, membangun kemitraan dengan para ahli dibidangnya yang akan melatih para penerima manfaat, juga membangun dan melakukan pemetaan untuk pemasaran hasil panen. Selain itu juga tim pendamping 
dari lembaga pengembang ummat (LPU) tidak melupakan monitoring dan evaluasi sebagai wujud mengukur keberhasilan dan kegagalan program.

\section{Output dan outcome (Hasil dan Dampak)}

Berdasarkan temuan lapangan menunjukkan bahwa proses pemberdayaan yang dilaksanakan oleh Lembaga Pengembang Ummat (LPU) melalui program penguatan pemuda dibidang budidaya ikan lele dianggap satu hal yang tepat sasaran. Masyarakat dampingan sebelum pendampingan masih mengalami kesulitan dalam bidang ekonomi, namun pasca pendampingan ada peningkatan pendapatan dalam bidang ekonomi.

Hasil lainnya adalah mereka terberdaya dalam bidang ekonomi dan menemukan pengetahuan baru tentang bagaimana melakukan budidaya ikan lele yang baik dan benar. Ada beberapa dampak langsung yang dialami pasca pelaksanaan program budidaya ikan lele, pertama: ada proses pengetahuan baru tentang budidaya ikan lele, kedua: terjalin mitra dengan berbagai stakeholder, baik dengan pemerintah gampong, Lembaga Pengembang Ummat (LPU), pasar dan tenaga ahli yang menjadi pendamping, Ketiga: memahami bagaimana mengatur keuangan dalam bisnis, keempat: meningkatkan partisipasi warga dalam bisnis, kelima: meningkatnya kreatifitas dan inovatif warga, keenam: mampu membangun komunikasi dan koordinasi dengan tim (penguatan organisasi)

Dampak tak langsung adalah mereka tanpa sadar telah mengalami transformasi dari masyarakat yang tidak memiliki semangat untuk bisnis menuju masyarakat yang kreatif dan inovatif. Pasca program ini berakhir, masyarakat telah mampu untuk mandiri dengan kelompok Sentra Kewirausahaan Pemuda dan mampu membentuk kelompok-kelompok usaha berikutnya tanpa harus menggantungkan diri pada pemerintah dan pendamping program.

\section{SIMPULAN}

Program Inkubator Bisnis ini memiliki dampak yang baik bagi masyarakat penerima manfaat khususnya pemuda. Dampak dapat berupa langsung maupun tidak langsung, menguatnya semangat berwirausaha dan partisipasi dalam wirausaha, kreatif, inovatif, menguatnya organisasi pemuda, terbangunnya nilainilai kebersamaan antar masyarakat, terjalinnya mitra dengan lembaga pendamping dan tenaga ahli, adanya proses transfer ilmu dibidang budidaya ikan lele, keberlanjutan program dan mampu menjadi pemberi semangat kepada pemuda-pemuda yang lain yang ada digampong tersebut.

\section{REFERENSI}

Alfrojems. (2019). Pengentasan Kemiskinan Perdesaan Melalui Pengembangan Ekonomi Kreatif, Pariwisata dan Modal Sosial. Sosio Informa, 5(2), 113-127. Retrieved from https://ejournal.kemsos.go.id/index.php/Sosioinforma/articl e/view/1752/994

Anna, N. E. V., Mannan, E. F., \& Srirahayu, D. P. (2019). Evaluation of the Role of Society-Based Library in Empowering Surabaya City People. Public Library Quarterly, 0(0), 1-13. https://doi.org/10.1s080/01616846.2019.1616271

Creswell, J. W. (2019). Research Design, Pendekatan Metode Kualitatif, Kuantitatif dan Campuran (4th ed.). Yogyakarta: Pustaka Pelajar.

Fernandez-Moral, M. J., Vidueira, P., Diaz-Puente, J. M., \&
Nicolas, V. L. De. (2015). Empowerment Evaluation in Spain: The Critical Friend Role in Working with Rural Communities. In Procedia - Social and Behavioral Sciences (Vol. 191, pp. 984-989). Elsevier B.V. https://doi.org/10.1016/j.sbspro.2015.04.483

Ife, J., \& Tesoriero, F. (2008). Community Development; Alternatif Pengembangan Masyarakat di Era Globalisasi. Yogyakarta: Pustaka Pelajar.

Iswadi. (2019). Pemberdayaan Masyarakat Melalui Pembinaan Kelompok Perikanan Dalam Meningkatkan Kesejahteraan Masyarakat. Jurnal At-Taghyir, 2(1), 1-13. https://doi.org/https://doi.org/10.24952/taghyir.v2il.1971

Iswari, I. G. A. Y., Indrayani, L., \& Suwena, K. R. (2019). Pemberdayaan Masyarakat Pesisir dalam Upaya Meningkatkan Ekonomi di Dusun Pangkung Dedari, Desa Melaya, Kecamatan Melaya. Jurnal Pendidikan Ekonomi, 11(2), 509-516. https://doi.org/http://dx.doi.org/10.23887/jjpe.vlli2.21550

K.Denzin, N., \& S.Lincoln, Y. (2009). Handbook of Qualitatif Research (lst ed.). Yogyakarta: Pustaka Pelajar.

M.B.Zubakhrum, Ponidjan, Ahyani, Setiadi, A., Abbas, U., Muladi, M., ... Anwar, M. H. (2013). Pedoman Pelaksanaan Fasilitasi Inkubator Bisnis Tahun 2013. Jakarta: Kemenpora R.I.

Matridi, R. A., Zuraidi, D., Setyadiharja, R., Sanopaka, E., Effendi, D., \& Utari, D. S. (2015). An Evaluation of P3DK ( An Acceleration of Development Village Program ): A Reviewing on Failure toward Revolving Loan Fund System in Kepulauan Riau Province, Indonesia. In Procedia-Social and Behavioral Sciences (Vol. 169, pp. 189-197). Elsevier B.V. https://doi.org/10.1016/j.sbspro.2015.01.302

Murdiansyah, I. (2014). Evaluasi Program Pengentasan Kemiskinan Berbasis Pemberdayaan Masyarakat (Studi Kasus Pada Program Gerdu-Taskin di Kabupaten Malang). Jurnal WIGA, 4(1), 71-92.

Naufal, A., \& Kusumastuti, Y. I. (2010). Evaluasi Program Pos Pemberdayaan Keluarga (POSDAYA) (Studi Kasus Posdaya Bina Sejahtera di Kelurahan Pasirmulya, Kecamatan Bogor Barat, Kota Bogor, Jawa Barat. Jurnal Penyuluhan, 6(2).

Noor, M. (2011). Pemberdayaan Masyarakat. Jurnal Ilmiah CIVIS, I(2), 87-99.

Ogamba, I. K. (2018). Millennials Empowerment: Youth Entrepreneurship for Sustainable Development. World Journal of Entrepreneurship, Management and Sustainable Development. https://doi.org/10.1108/WJEMSD-05-2018-0048

Saputra, A. (2013). Penguatan Pemuda Melalui Pengembangan Usaha Produktif (Budidaya Ikan Air Tawar Lele). Aceh Besar.

Sidik, F., Nasution, F. G. A., \& Herawati. (2018). Pemberdayaan Masyarakat Desa Menggunakan Badan Usaha Milik Desa: Desa Ponggok dan Kritik Terhadap Prestasi "Terbaik Nasional.” Jurnal Pemikiran Sosiologi, 5(2), 80-107. https://doi.org/https://doi.org/10.22146/jps.v5i2.44636

Sugiyono. (2013). Metodelogi Penelitian Kuantitatif, Kualitatif dan ReD. Bandung: Alfabeta.

Tong, A., Sainsbury, P., \& Craig, J. (2007). Consolidated Criteria for Reporting Qualitative Research (COREQ): a 32-Item Checklist for Interviews and Focus Groups. International Journal for Quality in Health Core, 19(6), 349-357. https://doi.org/10.1093/intqhe/mzm042 
Utami, B. N., \& Khonitan, D. (2018). Pemberdayaan Masyarakat Berbasis "Social Entrepreneurship" Bidang Pertanian dan Peternakan: Studi Kasus Desa Bukit Langkap Kabupaten Lingga, Kepulauan Riau. Jurnal Pemikiran Sosiologi, 5(2), 126147. https://doi.org/https://doi.org/10.22146/jps.v5i2.44638

Vina Salviana Darvina Soedarwo, Nurul Zuriah, Ratih Yuliati, S. (2017). Pemberdayaan Masyarakat melalui pendidikan non formal Berbasis Potensi Lokal Dalam Membangun Desa Wisata Adat. Jurnal Sosiologi Pendidikan Humanis, 2(2), 96-102. https://oi.org/http://dx.doi.org/10.17977/um02lv2i22017p0 96 